\title{
FAULT ANALYSIS OF GEARBOXES IN OPEN PIT MINE
}

UDC: 621.833 .01

Original scientific paper

https://doi.org/10.18485/aeletters.2020.5.2.3

\author{
Milan P. Vasić ${ }^{1}$, Blaža Stojanović ${ }^{1}$, Mirko Blagojević ${ }^{1}$ \\ ${ }^{1}$ Department for mechanical constructions and mechanization, Faculty of Engineering, University of \\ Kragujevac, Serbia
}

\begin{abstract}
:
The paper presents the results of testing gearboxes in coal open pit mine which have been damaged by various mechanisms. Gearboxes, as constituents of belt conveyors, bucket-wheel excavators and bucket chain excavators and spreaders, are the most loaded segments of drive units the functionality of which affects the operation of complete coal and overburden systems. Therefore, special attention has to be paid to their condition so that the analysis of relevant condition indicators could lead to correct conclusions as to their functionality, as well as point to the factors causing their fault. Tests were carried out on 95 gearboxes throughout 2017, during general repairs at Drmno mine workshop. After examination, all identified failures were illustrated with an appropriate photo, classified according to the appropriate standard, and described in the form of manifestation and cause. The research has shown that the most dominant were faults of bearings and lubrication, whether seals and cuffs or a thin hermetic layer between the housing and covers. In addition, some of the faults happened on gears and toothed and stepped shafts. Major irregularities in operation, resulting from damage to gearbox elements, are show by fault tree analysis (FTA).
\end{abstract}

\section{ARTICLE HISTORY}

Received: 04.05.2020.

Accepted: 10.06.2020.

Available: 30.06.2020.

\section{KEYWORDS}

Gearboxes, Fault information visualization, Wear type statistic, Fault tree analysis (FTA)

\section{INTRODUCTION}

In lignite open pit mines there are many different complex systems (belt conveyors, bucketwheel excavators and bucket chain excavators and spreaders) consisting of a number of mechanical subsystems, where, among others, special role and importance is attributed to gearboxes.

Their heavy exploitation, accompanied by loads with pronounced dynamic and stochastic character [1], gives rise to failures in both structural and mechanical parts.

Gearboxes are expected to operate 24 hours a day in running order. Unplanned shutdowns due to faults result in high maintenance risks and production costs [2]. High costs are triggered by production shutdowns, losses and the urgent procurement of spare parts. High risks are associated with possible injuries to workers and secondary damages to adjacent subsystems.

According to Matuszewski [3], in considered lignite mine, as much as $14 \%$ of gearboxes can be replaced each year due to unexpected failures such as gear and bearing failures.

To avoid such a scenario, several types of maintenance have been developed, from breakdown maintenance to condition-based and proactive maintenance [4]. Implementation of condition-based maintenance involves monitoring the operating condition of gearbox based on degradation-sensitive physical parameters. These parameters are obtained by measuring vibration, noise, temperature, and oil condition analysis [2].

The importance of monitoring condition is shown by Zimroz and Król [5] who compared the total number of identified faults on belt conveyor 
gearboxes over a 13-year period. If we compare 1993 when up to 29 gearboxes failed with 2006 when only 4 gearboxes failed, we can conclude that introduction of condition-based monitoring significantly reduces the number of faults. Of these, faults most frequently occur on the inlet elements in the gearbox. According to Scoć [6], who analyzed drive units at underground mining machines, the percentage is over $50 \%$, which is expected as the highest rpm, highest temperatures and start-up shocks are found at the inlet.

Bartelmus [7], points out that fault is not the process of development of a single defect. Considering the condition monitoring for cracks and tooth fracture, it should be taken into account that crack and tooth fracture can be the result of several events, such as, for example, bearing wear, which secondarily causes shaft and gear misalignment.

In addition to the condition monitoring technique, we need to have knowledge of wear and failure processes. However, monitoring condition of technical systems in the mining industry is not as well developed as in other industries [5]. Most studies focus on identifying failures by measuring vibrations, pointing it out as the most reliable method as each gearbox is considered to have normal vibrations in certain frequency bands, until an error occurs, which greatly increases vibrations [8]. In addition, most studies were carried out on simple gear and bearing failures, not expounding other types of possible failures, changes that occur on gearbox elements, or the causes that lead to them.

This paper discusses typical gearbox element failures as well as typical changes to the condition of lubricating oil. Each individual failure or condition change is identified and illustrated with an appropriate photo, classified according to the appropriate standard, described in the form of manifestation and cause.

The research was carried out on 95 gearboxes that were collected throughout 2017, during general repairs at Drmno mine workshop.

\section{TYPICAL GEARBOX ELEMENT FAILURES}

Toothed gear failure implies changes to the mechanical elements that result in the total or partial loss of working capacity of the gearbox under consideration. In this case, several types of failures on multiple elements can occur simultaneously on a single gearbox, but as a rule, one of the resulting types is dominant and will essentially determine the further direction of tribological process development.

Since gearbox elements differ in their purpose, characteristics and geometry, element failures will be viewed separately.

\subsection{Typical gear failures}

Gear failures and damages are numerous. They mostly occur on the teeth and almost never on the body. If not discovered in time, the consequences could be catastrophic.

According to ISO 10825 [9], more than 20 types of failures have been defined that are classified in six main groups, and include: surface deterioration, scuffing, permanent deformation, surface fatigue phenomena, cracks and tooth fracture.

Surface deteriorations occur on the working surfaces of tooth flanks from the very beginning of exploitation [10-12]. Over a longer period, they also result from the effect of dirt, mechanical impurities in oil, or wear products that reach the coupling zone. They are manifested by the occurrence of dents, notches, grooves and scratches in sliding direction [11], as shown in Fig.1.a and 1.b. Failures first occur between the pitch and root circle, and then between the pitch and tip circles, only to spread on the entire surface of tooth active part [10]. Depending on the form of emergence, we differ among: sliding wear, corrosion, overheating and erosion [9].

Scuffing occurs on the working surfaces of tooth flankes, most often between the tip and root circle [10]. It is formed as a result of oil film disruption, local metal contact, sudden temperature increase due to friction, local welding and tearing of welded particles [10-13]. It is manifested by the appearance of creases and notches in the sliding direction. An example of pronounced scuffing due to a large deviation in the parallelism of coupled gears axes is given in Fig.1.c.

Permanent deformations occur on the tip, side, and very often on the entire tooth. They are formed as a result of high loading, impact due to the large side clearance, interruption of lubrication which leads to warming and reduction of gear material strength, as well as when foreign particles pass through coupling [10-12]. They are manifested by the appearance of dents, creases or complete reshaping of tooth parts. Examples of permanent deformations due to the presence of chipped parts of other elements in the coupling are given in Fig.1.d and 1.e. 

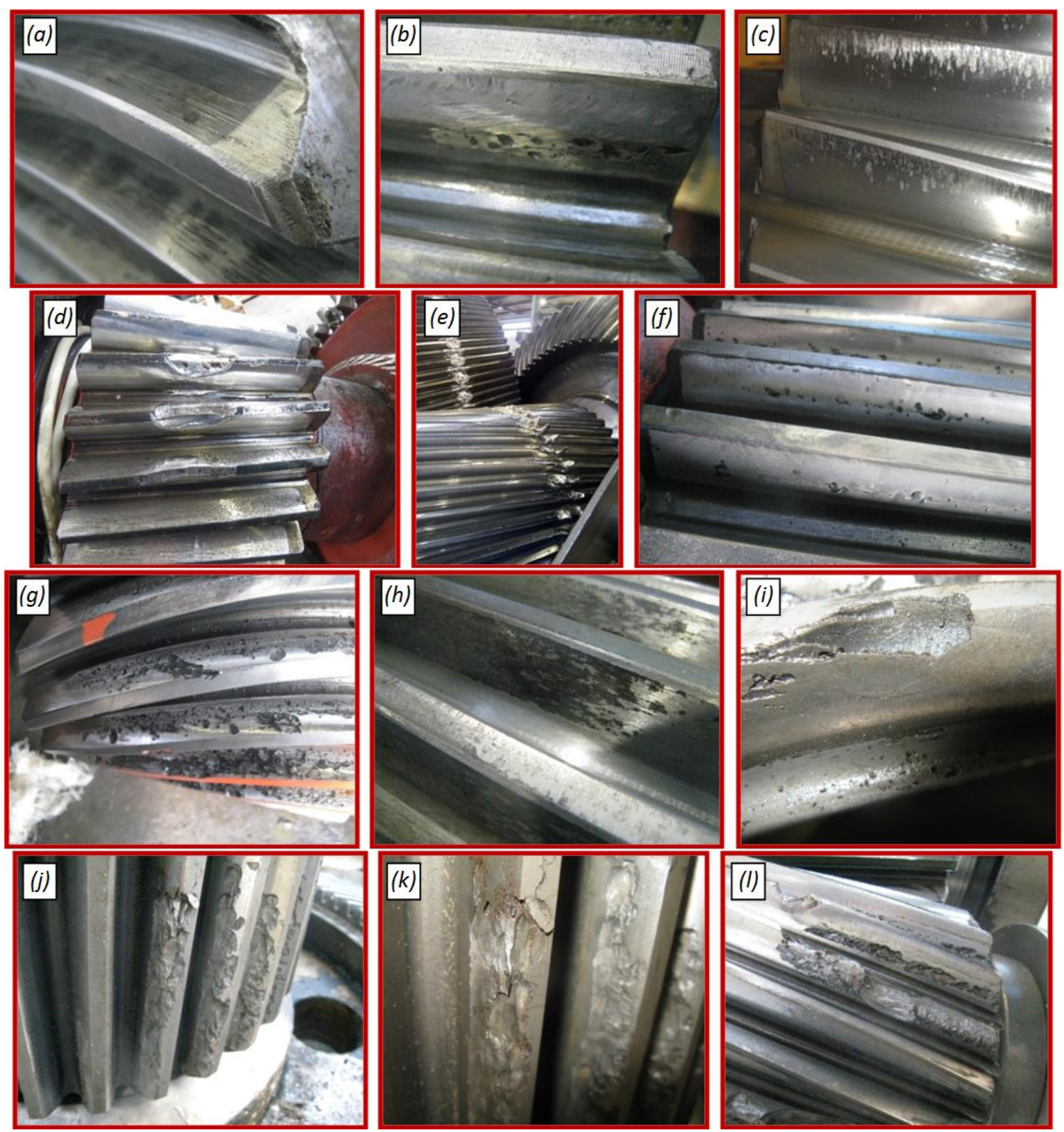

Fig.1. Typical gear failures on analyzed gearboxes

Surface fatigue phenomena occur most often on the working surfaces teeth sides. They result from the mutual contact of the teeth in the coupling, which results in displacement of the superficial layers on contact surfaces $[14,15]$. As a result of constant displacement, fatigue occurs that can be divided into three phases [11]. The first phase is the initiation of a crack at or just below the surface, most often at the sites of various irregularities in the crystal structure. In the second phase, due to variable normal voltages, cracks grow, and in the third phase, parts of material are chipped, creating a characteristic relief in the form of smaller or large holes (Fig.1.f). Depending on the method of formation, development, shape and impact on service life, according to ISO 10825 [9], fatigue wear is classified into: initial pitting, progressive pitting (Fig.1.g), micro pitting (Fig.1.h). flake piting (Fig.1.i), spalling (Fig.1.j) and case crushing.

Cracks most often occur in the root or side of a tooth, sometimes on the gear body. They are caused by quenching, grinding or fatigue [14]. They are manifested by separating the material crystal lattice, and creating a new surface. Quench cracks occur during heat treatment due to excessive internal stresses and are detected only after a certain operating time. Grinding cracks are generally short, not very long and regularly distributed, and occur during or after grinding. 
Fatigue cracks (Fig.1.k) result from cyclic loads the intensities of which are most likely lower than the material tensile strength.

Fractures most often occur at the root or in the middle of the tooth side, sometimes also on the gear body, independently or as a result of tooth fracture [10]. They occur as a result of overloading, tooth shear, plastic deformation, or material fatigue [14]. They are manifested by the loss of material from larger surfaces, and an example of such a material fatigue fracture is shown in Fig.1.I. Overloading fracture is brittle, ductile, or quasibrittle, and results from the effect of great load [14]. Shear fracture is characterized by a cut surface, similar to that of machining. Fatigue fracture has two specific zones at the fracture surface: fatigue region and final fracture region. The fatigue region is relatively smooth-matte, and the final fracture region is relatively rough, coarsegrained and rugged.

\subsection{Typical shaft failures}

Shaft failures and damages are not as numerous as that of gears. They can be classified into: surface deteriorations, surface fatigue phenomena and shaft fractures $[16,17]$. Surface deteriorations mainly occur on the outer surfaces, which results in an increase in the radial clearance between the shafts and the elements mounted on them, and shaft fractures have far greater consequences.
Surface deteriorations, shown in Fig.2.a, occur at locations of relative displacement of firmly mounted parts such as bearings, gears, and couplings. They are manifested by the appearance of dark brown spots that represent fretting corrosion (Fig.2.a), as well as by the emergence of clefts in the rotating direction (Fig.2.a) which represents abrasive wear.

Surface fatigue phenomena occur on the stacked parts. They are caused by the relative displacement of elements along the shaft in cycles $\mathrm{n}$ times. They are manifested by the appearance of smaller or larger holes, forming a characteristic relief in phases (Fig.2b), as in gears.

Shaft failures most often occur on the input shafts of the worm and bevel gears, which are made as a one piece with the shaft, at places of pronounced discontinuities in cross section sizes. They occur as a result of overloading, plastics deformations or fatigue, and each type of fracture is manifested by the characteristic appearance of the fracture surface [16]. In case of overload, the fracture surface is relatively rough. In case of shaft fatigue fracture, the fracture surface is relatively smooth, and the final fracture is relatively rough. An example of such a fracture is shown in Fig.2.c, and 2.d, where a characteristic rough portion representing the final fracture can be observed, while the rest of the fracture surface is smooth. Bending stress fractures are perpendicular to the shaft axis, just as in Fig.2.c and 2.d, while torsional stress fractures are often set at an angle of $45^{\circ}$ to the shaft axis of the, just as in Fig.2.e.

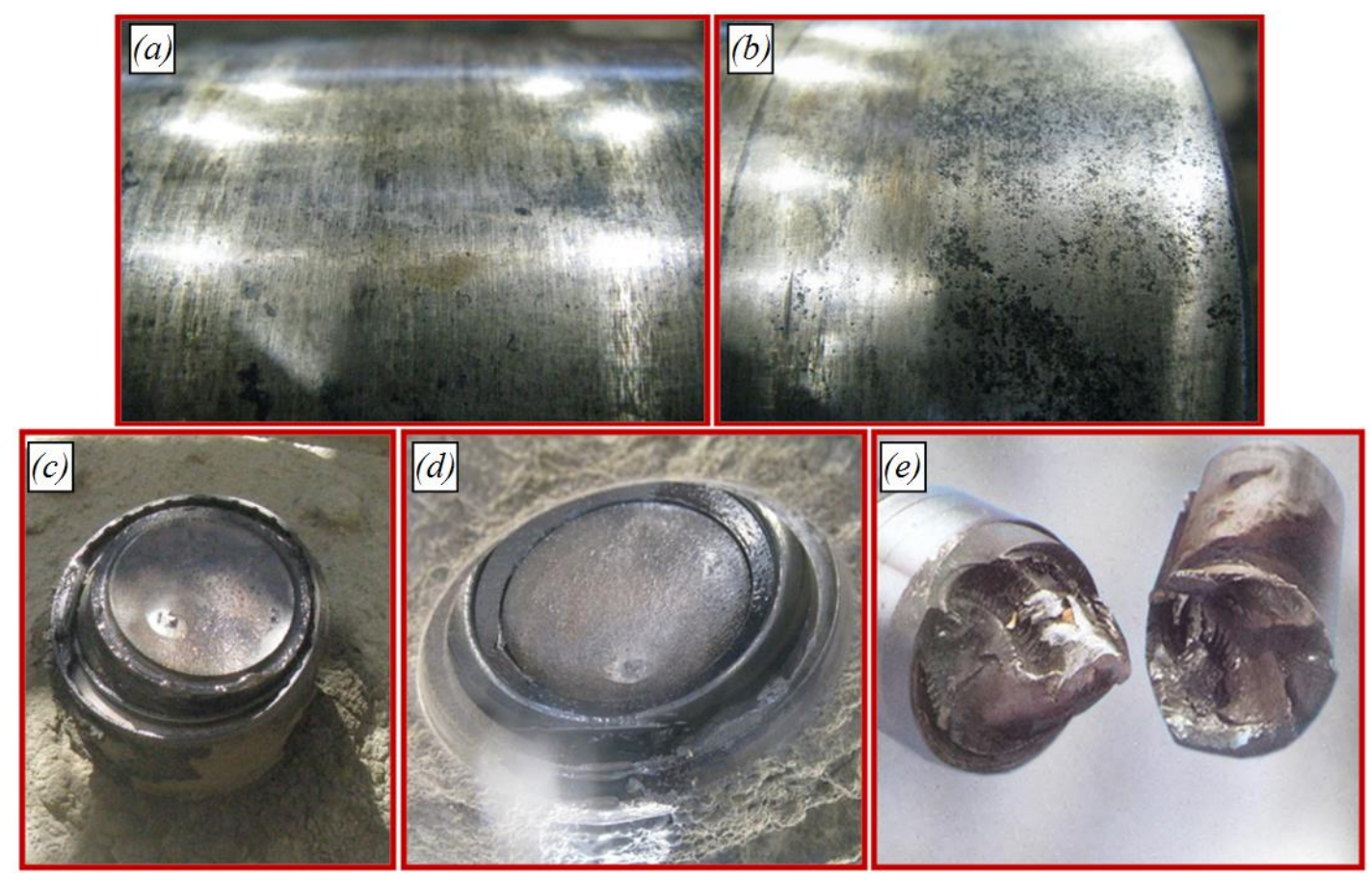

Fig.2. Typical shaft failures on the analyzed gearboxes 


\subsection{Typical bearing failures}

Bearing failures and damages are numerous. They occur on almost all elements: rings, cages, rolling bodies and seals [11]. According to ISO 15243 [18], all failures can be classified into 6 major groups, which include fatigue (pitting), abrasive and adhesive wear, corrosion, electroerosion, plastic deformation and fracture.

Fatigue (pitting) is the result of cyclic stress that develops at the contact surface [11]. It is manifested by the appearance of pits in the initial phase and the destruction of the contact surface in the final phase [19-21], creating a characteristic relief, as in gears and shafts. An example of pitting on a double-rowed roller bearing is shown in Figu.3.a, while Fig.3.b shows an example of pitting on a bronze cage of a roller bearing.

Abrasive wear occurs as a result of the effect of hard particles that have reached the contact zone during bearing operation [11]. Hard particles are often chipped parts of the bearing elements themselves. Also, particles can be contained in the lubricant, in case there is no filtering, or due to the cavitation of the lubrication inlet pipelines [21]. They are manifested by damaging the contact surfaces in the form of notches (Fig.3.c), grooves and scratches.

Adhesive wear occurs as a result of poor lubrication, when the oil film thickness is not great enough to completely separate surfaces in contact with each other [11]. In such conditions, at places of rolling bodies with considerable pressures, heat is generated and adhesion forces are formed, that is, instantaneous micro-welding occurs [19-21]. It is manifested by the removal of material from the surface, accompanied by discoloration due to heating and softening of the material.

Oxidation corrosion is caused by the presence of moisture. It is manifested by the appearance of oxide coatings of different thicknesses and colors: thin - relatively light $(<40 \mu \mathrm{m})$, medium - light brown and gray $(<500 \mu \mathrm{m})$, as well as thick usually dark coatings $(>500 \mu \mathrm{m})$ [11]. As the thickness of the oxidized coatings increases, they burst and are removed from the surface, leaving a relief surface. An example of oxidation corrosion on the outer bearing ring is shown in Fig.3.d.
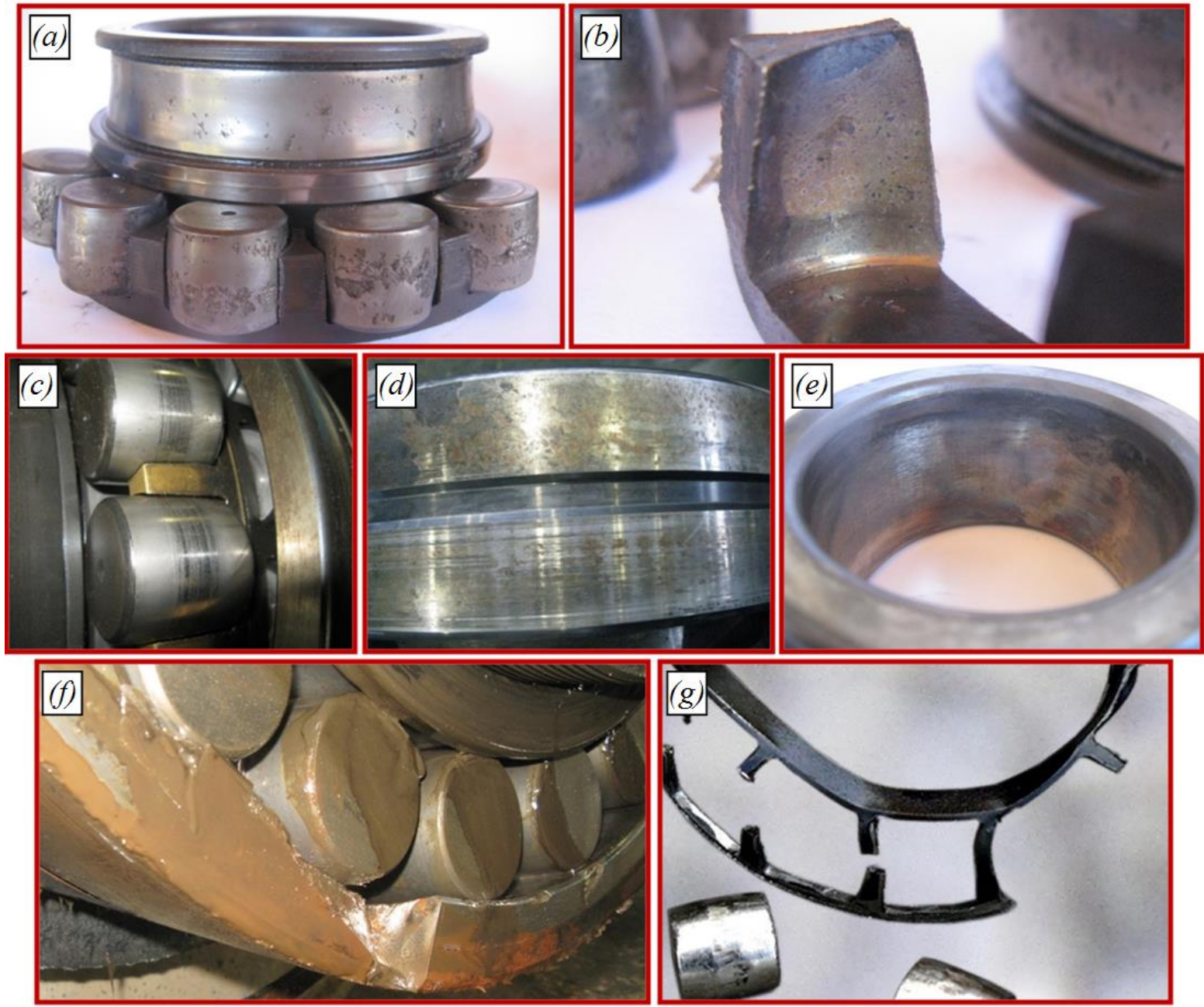

Fig.3. Typical bearing damages on the analyzed gearboxes 
Fretting corrosion occurs when there is a gap between the shaft and the inner ring or housing and the outer ring [19-21]. The gap allows for the relative displacements of the aforementioned parts resulting in chipping of small particles of material. It is manifested by red oxide coatings or black coatings in the presence of oil or borax peroxide (rust) coatings in the presence of moisture [11]. An example of fretting corrosion on the inner bearing ring is shown in Fig.3.e.

Plastic deformations occur as a result of impact and uneven loads or irregular mounting [19-21]. They are manifested by dents or partial changes in the shape of damaged surface. Improper mounting may result in the formation of dents most often on outer and inner rings, as well as on seals. Also, plastic deformation may occur if oil contains hard particles of some foreign material, e.g. worn cage or ball particles. These particles cause dents in the rolling path and cause damage to all the inner parts of the bearing.

Fractures occur due to overloading or material fatigue [19-21]. They are manifested by the loss of material from the damaged element surface. Overload fracture is usually caused by rough handling (impact) when the bearing is mounted or dismantled (Fig.3.f), by use of inadequate tools during mounting, or when the bearing is hammered onto an incorrect shaft diameter. Fatigue fracture occurs at sites where surfaces have already been affected by pitting. In this case, cracks continue to grow until complete fusion and final fracture of the element. An example of cage material fatigue fracture is shown in Fig.3.g.

\subsection{Typical housing failures}

Hosing failures and damages are not as numerous as that of gears and bearings. They can be classified into: surface deterioration (abrasive wear and corrosion) and sealing failures. Fractures and cracks are very rarely found in places of bearings, ribs and other parts, although this is not impossible.
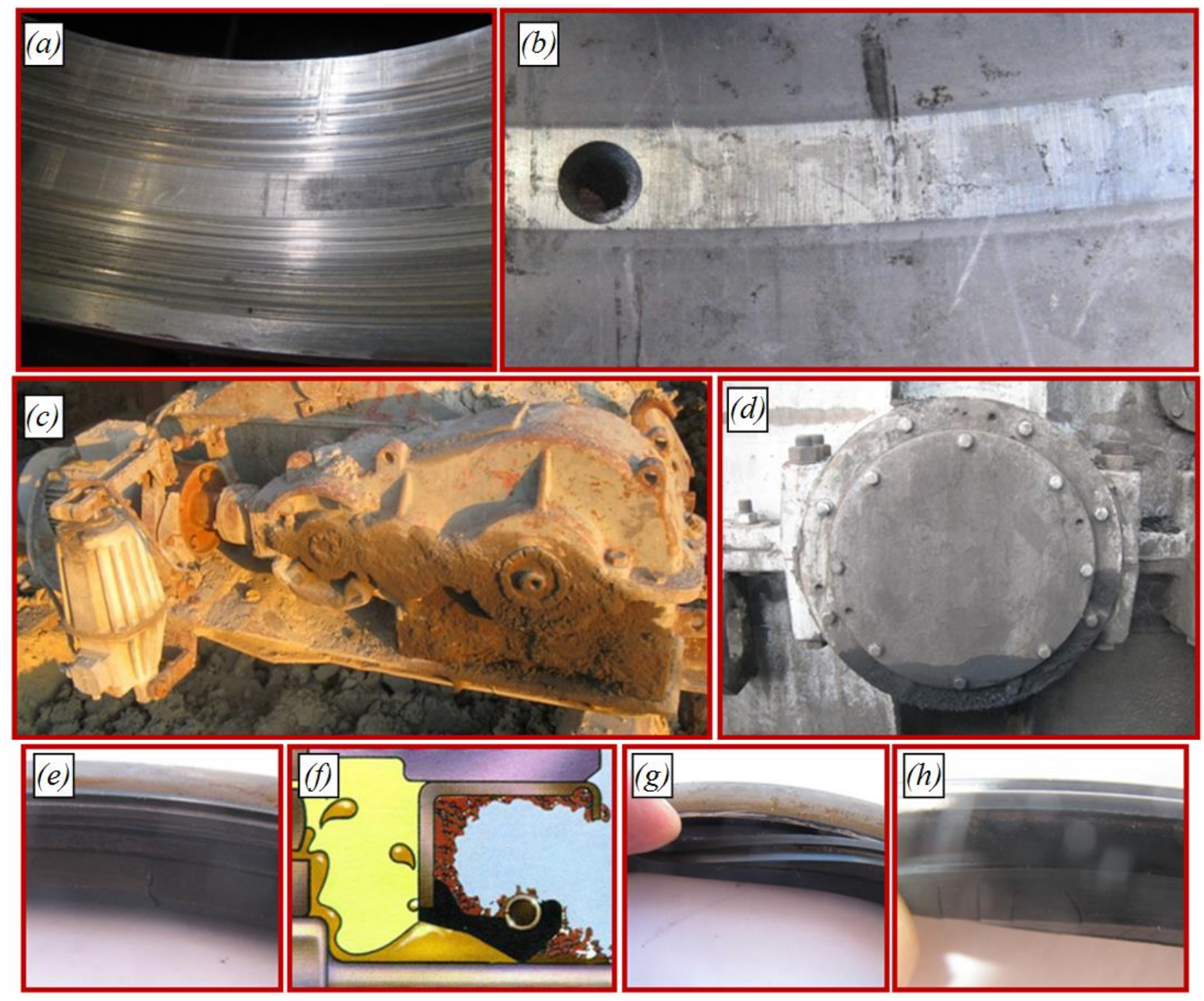

Fig.4. Typical housing failures on the analyzed gearboxes 
Abrasive wear occurs on the resting surfaces of covers and housings. They are manifested by the appearance of dents, notches, grooves, and scratches in the rotation direction [11]. Fig.4.a shows the consequence of slippage of the outer ring of a two-row roller bearing. Abrasive wear can also occur in the axial direction, or in the direction of transverse shaft, as shown in Fig.4.b. Such wear occurs if the screws on the side covers are not tightened enough, so there is a gap which, due to vibrations, allows the bearing to have smooth axial displacement. Often, transverse failures may also occur when replacing bearings in the mechanical room.

Oxidation corrosion is caused by the presence of moisture, and almost all housings are exposed to atmospheric precipitation. It is manifested by the appearance of oxide coatings of various thicknesses and colors, as in bearings. An example of a partially oxidized housing is shown in Fig.4.c. First, the oxidized layer is formed at the places of damaged surface protection, such as edges of a smaller radius, or surfaces damaged during mounting/dismantling, and then the oxidized layer tends to spread, with layer thickness depending on the material characteristics, surface protection, temperature and the amount of moisture.
Sealing failure occurs on the cuff seals, the thin layer of sealant between the housing and cover, and due to insufficient tightening of cover screws [16]. They are manifested in many ways. Fig.4.d shows an example of oil leak due to the sealant failure on the side cover. Fig.4.e shows an example of notched rubber lining when mounted on a shaft with a wedge groove. Also, during mounting, the spring that presses the rubber lining may be damaged or may come out of its groove. Sometimes it is improperly set as shown in Fig.4.f. Excessive exposure to high temperatures causes rubber to harden and crack, as shown in Fig.4.g. Also, during exploitation, the rubber liner can separate from the tin L profile (Fig.4.h), which also causes oil to leak.

\section{TYPICAL LUBRICANT PROBLEMS}

Typical lubricant problems include oil degradations that cause negative lubrication changes, resulting in wear and failure of the gearbox components. They can be classified into: oil foaming, oil oxidation, water penetration into oil, oil contamination with foreign materials [22, 23].
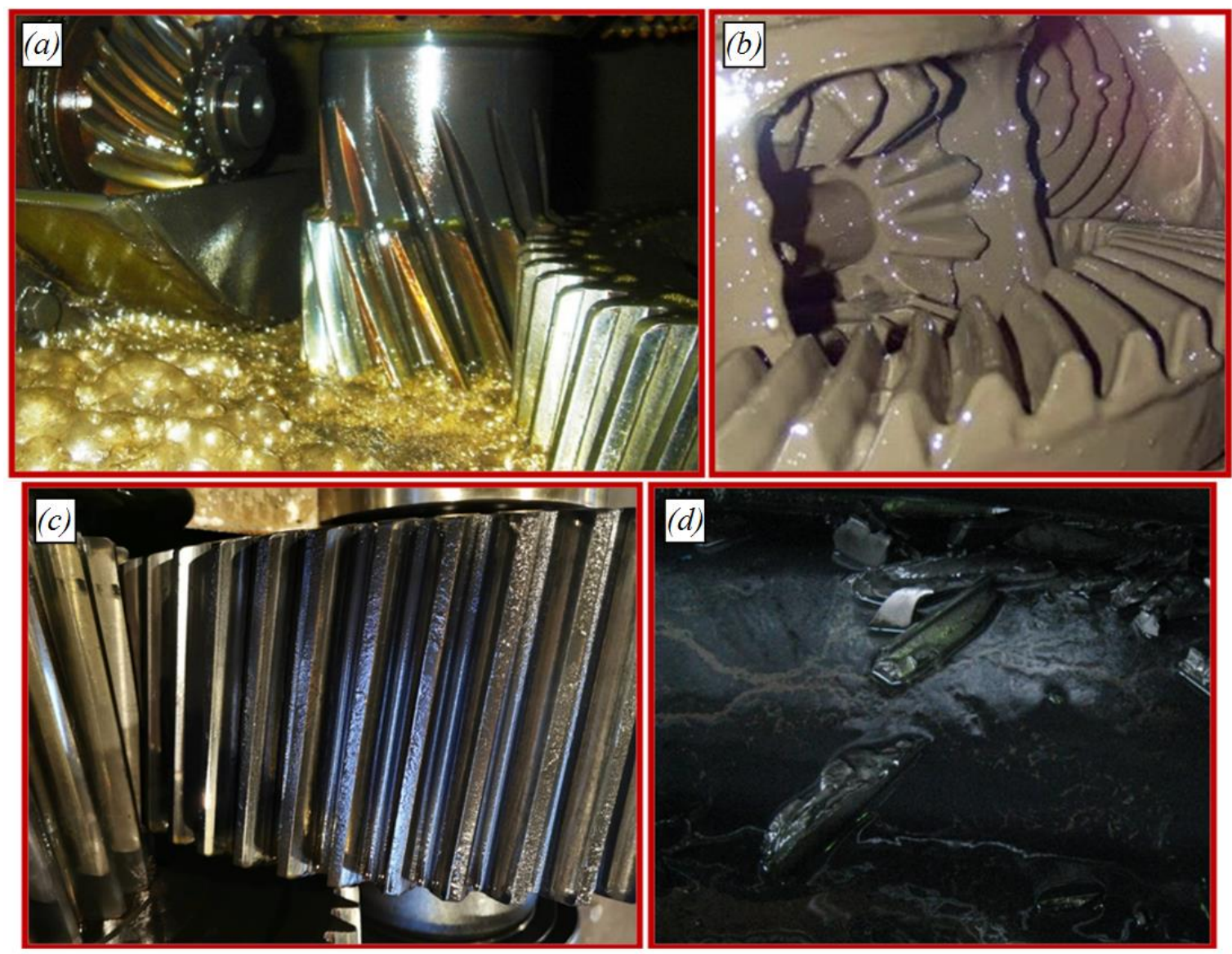

Fig.5. Typical lubricant problems 
Oil foaming occurs due to the application of inadequate viscosity oil, due to the low or too high oil level, air penetration, mixing oil with another oil of different viscosity, oil contamination with dust and water [23]. It is manifested by the appearance of small air bubbles on the lubricant surface. Formed foam impedes oil temperature maintenance, accelerates oxidation processes and stimulates aeration, which results in intense cavitation, poor lubrication, and reduced service life of the oil itself. An example of oil foaming in a cylindrical bevel gearbox is shown in Fig.5.a.

Oil oxidation is the chemical reaction of oil with oxygen. This is an inevitable occurrence that causes oil to age and cannot be prevented. Appearance of oil oxidation leads to an increase in viscosity, formation of varnishes, sediments and deposits, additive consumption, an increase in acid numbers, and the appearance of corrosion on the gearbox elements [22]. It is manifested in oil color change, blurriness, darkening and sludge formation.

Water penetrates the lubricant due to sealing failure and remains in the gearbox as dissolved, emulsified and free. Below the saturation level, water molecules are dispersed next to oil molecules, resulting in water in oil that is not visible. When the amount of dissolved water exceeds the saturation limit, oil can no longer absorb water molecules, which results in emulsification. It is manifested by the characteristic misty appearance of oil, as shown in Fig.5.b. Further increment of water in oil results in water and oil levels separation, which causes water to settle at the bottom due to lower density. Water in oil significantly affects viscosity increase, formation of deposits, foaming, which results in oil film strength reduction and the appearance of cavitation.

Oil contamination with different impurities is due to residues of the materials used in gearbox repair (metal scrap, sealant material), materials from the atmosphere or the working environment (water, dust, sand, etc.), materials formed by gearbox parts wear or corrosion (Fig.5.c). Very often, gearbox oil looks flawless macroscopically, but it actually contains many microscopic particles. The consequences of the presence of particles depend on their size in relation to the clearance of gear in the coupling and bearing elements. Severe failures may occur if the particle diameter is similar to the clearance size. In this case, the particle fits into the contact/coupling zone where pressures are significantly high and leads to abrasive wear.
An example of chipped teeth in oil is shown in Fig.5.d.

\section{FACTORS LEADING TO FAILURES}

Gearbox wear depends on a number of different factors that can be classified into 6 main groups: operating loads, operating conditions, material, production, mounting and structural design. It should be emphasized that a number of factors are common to all elements of the gearbox.

Operating loads include bending stresses at the tooth base, tooth shear stress, contact pressure on the tooth side, shaft misalignment, bending and twisting stress of the shaft, surface pressure between the bearing elements, or all phenomena that occur during the transmission of power.

Operating conditions imply inadequate type of lubrication, impurities in oil, insufficient oil viscosity, inadequate oil, and insufficient oil content. Conditions that occur during exploitation are generally different from those in calculation. Teeth flanks surfaces must theoretically be separated by an oil film between the current points of contact and movement. However, favorable lubricant layer cannot be created each time, so direct metal-to-metal contact occurs, resulting in contact surface wear.

Material defects occur as a consequence of casting imperfection, e.g. inclusions, pores, gas bubbles, layered and incoherent structure.

Production defects include poor machining (dimensional errors and roughly machined surfaces), errors in heat treatment (too soft or too tight gear).

Mounting defects include poor toothing, improper clearance adjustment and improper handling. Installation must be carried out on suitable working surfaces, in dry dust-free conditions. Impurities such as: metal shavings, sawdust, sand, corrosive liquids must never enter the gearbox, as they would cause wear on the gearbox components immediately after starting work.

Structural defects can cause excessive stresses. This is primarily related to sudden changes in the shafts cross-sections and insufficient stiffening of bearing grooves on housings. Even when failures occur, it is very difficult to determine structural defects and their impact on failure.

\section{RESULTS AND DISCUSSION}

The results of the research done on 95 gearboxes withdrawn from exploitation in 2017 
show that failures are the most likely to occur on oil seals $(40.1 \%)$, whether cuff seals or a thin layer of sealant, as well as on bearings (38.8\%), Fig.6. If oil leakage is minimal or does not require greater amounts for topping, the gearbox will operate under such conditions until the failure of another element that would require total shutdown. As a result of incomplete sealing, water, dust, and other undesirable particles penetrate the inside of the gearbox.

Bearing failures are most often manifested by gaps due to abrasive wear, oxidation corrosion, mounting defects, shaft misalignment, gear failure, and to a lesser extent bearing element fractures. All this results in a rise in temperature, vibration and noise.

In addition to bearings, a number of failures occurred on gears: bevel (4.2\%), cylindrical (1.3\%) and worm (1\%), as well as on shafts: inlet toothed $(3.5 \%)$, central toothed $(0.3 \%)$ and stepped with groove $(0.3 \%)$, Fig.6. Almost all of these gears, except one cylindrical, failed at the inlet of the gearbox, as expected. The highest rpm is at the inlet, usually $1000,1500 \mathrm{~min}^{-1}$. There are the highest temperatures and the greatest shocks at startup as well. Gear failures are most commonly manifested by pitting, spalling, tooth fractures and permanent deformations. All this results in an increase in vibration and noise.

The third group of elements consists of failures of coupling rubber inserts $(5.3 \%)$, screws $(1.7 \%)$ mounted on covers, Fig.6. The consequences of failure of these elements are far less.

The number of failures occurring during one year could be minimized through more regular inspections, preventive and corrective activities.

\section{FAULT TREE}

One of the most suitable methods for analyzing the most likely causes of gearbox failure is the Fault Tree Analysis, which is shown in Fig.7. The unwanted, top event, defined as "gearbox malfunction" may be complete or partial. If the gearbox loses its function, the malfunction is complete. On the other hand, if the gearbox works but its performance is significantly impaired, then the malfunction is partial.

Generally speaking, general complex events representing malfunctioning and resulting from the analyzed gearbox element failures include:

- increased noise;

- oil foaming;

- increased oil viscosity;

- oil leakage;

- high temperature;

All general complex events are further developed to the causes that lead to their occurrence. It should be emphasized that a number of causes in the fault tree are common to all complex events.

The causes of noise increase are usually related to gearbox element failure, primarily bearings and gears, or to lubrication with regard to insufficient amount of oil, application of inadequate oil, or oil of insufficient viscosity. However, noise does not have to be due solely to exploitation conditions. The cause may also be a faulty mounting in the form of poor toothing or mounting bearing with a larger clearance than permitted.

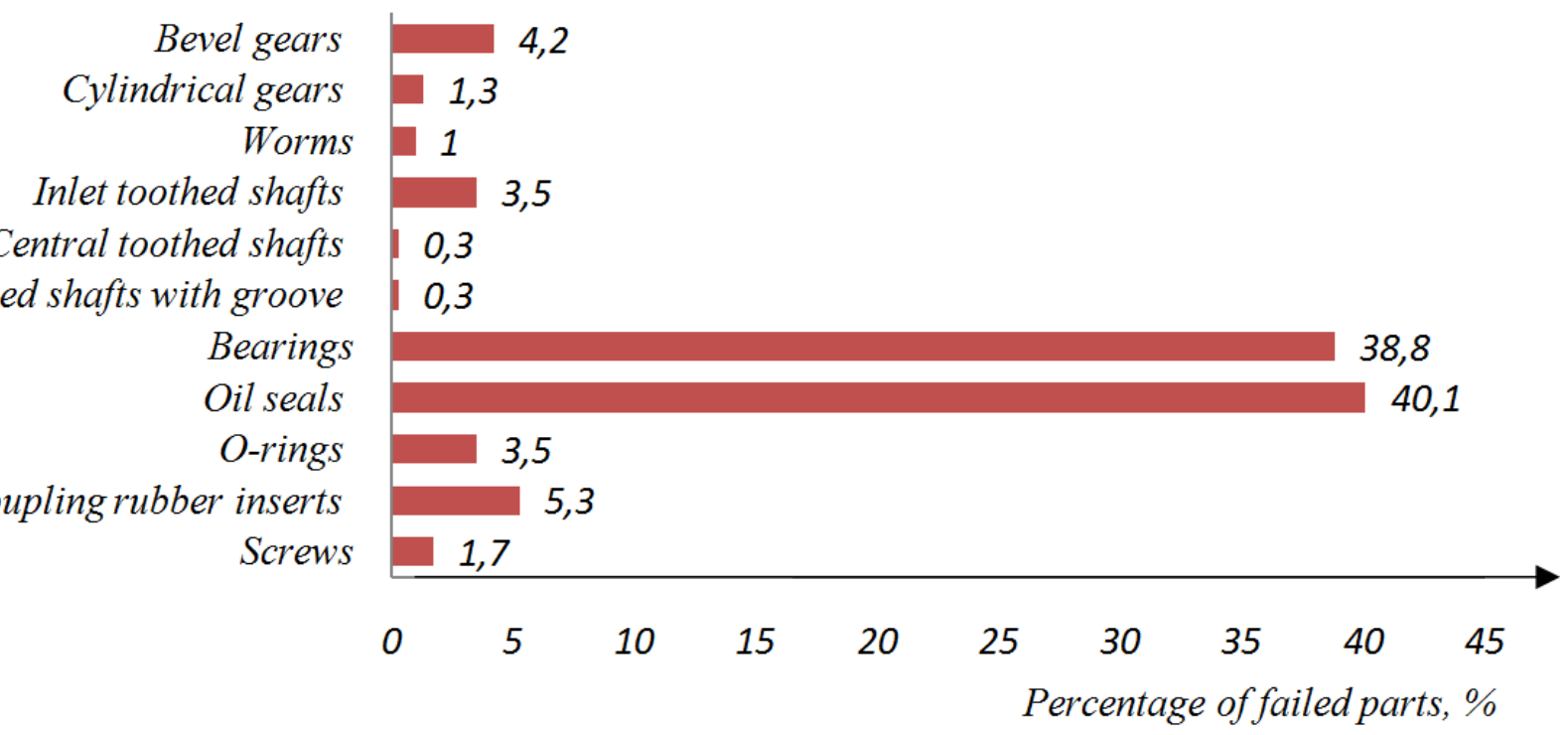

Fig.6. Percentage of occurrence of various types of failures on the tested gearboxes 
The cause of oil leakage is usually damaged sealing. Possible types of seal failures are given in Chapter 2.4.

The cause of oil foaming is high oil level. In such a situation, oil is swirled and air enters the oil. Also, water, as well as some types of additives, in oil can cause foaming at elevated temperatures.

Causes of oil viscosity increase include contamination of oil with higher viscosity oil, oxidation of oil due to high-temperature operation, and contamination with foreign materials, e.g. water, dust, wear products.
The causes of gearbox temperature rise are generally related to insufficient oil content. Also, rising temperatures may be due to increased friction. The causes of increased friction are inadequate oil, overloads, excessive rpm, and high impact loads.

A developed fault tree should not be considered complete. In the present case, it may be complemented by other events with less likelihood of occurrence. Grouping of original events, as well as defining complex events, can be done in another way as well.

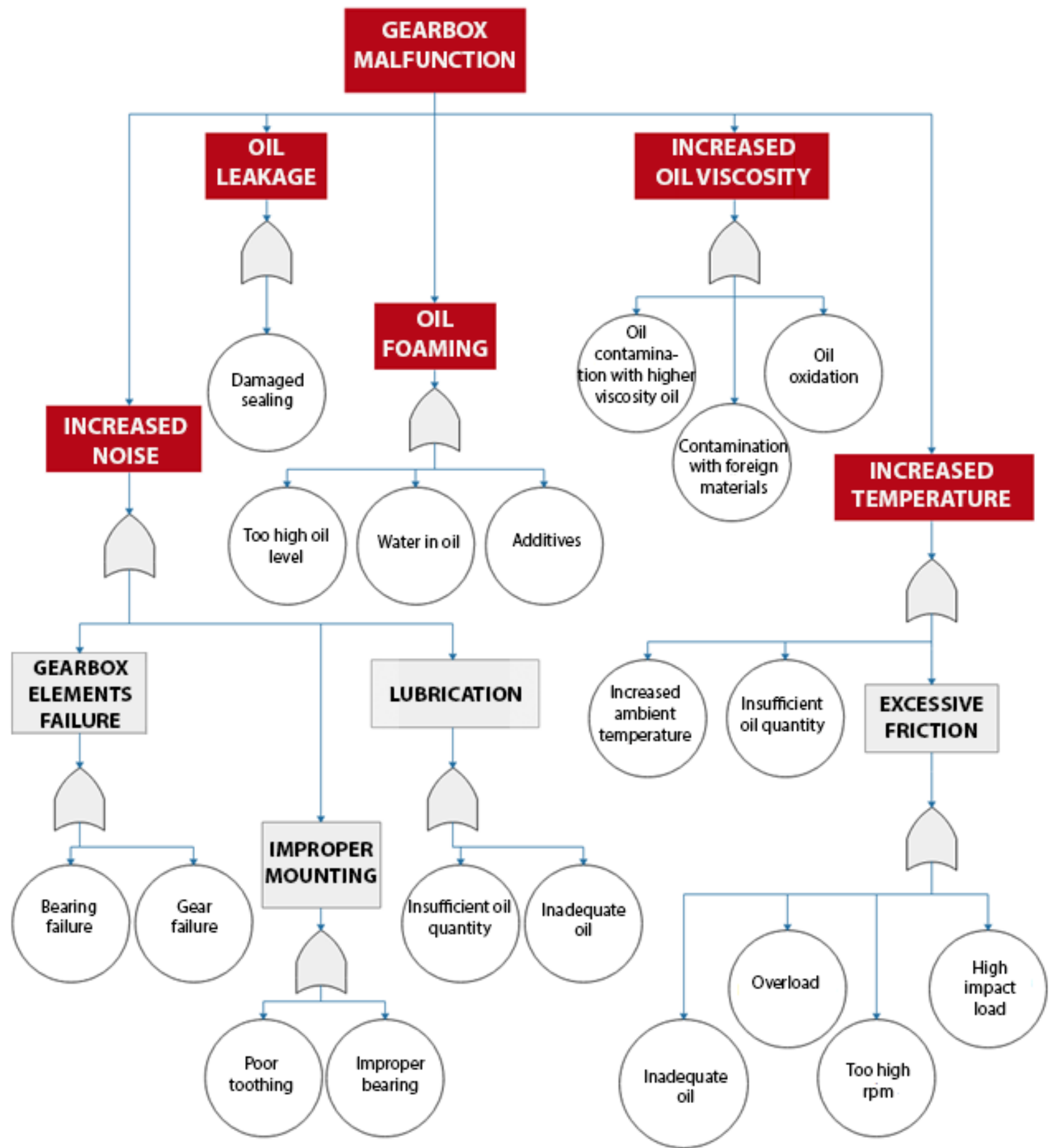

Fig.7. Fault tree of analyzed gearboxes 


\section{PREVENTIVE AND CORRECTIVE MEASURES}

A large number of failures, which lead to gearbox malfunction unit, can be affected by corrective and preventive measures. Based on the analysis conducted, it was concluded that all three lubrication regimes are present: boundary, mixed and hydrostatic. Corrective measures can be implemented in the form of using lubrication systems which would completely or at least partially eliminate the boundary lubrication regime.

Second, lubrication with unfiltered oil should be completely avoided. Unfiltered oil contains metal scraps created by contact surface wear. Such oil is directed by nozzles into the contact zone, between the rolling elements and the ring, as well as in the gear coupling. The consequences are destruction of the contact surface in the form of dents, notches, grooves and scratches, as described in previous sections. Corrective measures can be achieved using finer filters with a mesh of $60-150 \mu \mathrm{m}$, provided that the mesh density corresponds to the viscosity of the applied oil.

For gear lubrication, corrective measures can be achieved using fan-shaped nozzles instead of round ones, since this would cover a much larger tooth surface.

Replacing gearbox oils is mostly done during the planned overhaul, unless the gearbox fails in the meantime. Protection against high pressures and impact loads, resistance to oxidation, resistance to corrosion, ability to extract water and other abilities are achieved by additives, and oil stability changes with exploitation hours. The estimated operating hours of used oils (Famredol ultra 220, Kompaund ASP-220, Meropa 220, etc.) are $4000-6000 \mathrm{~h}$. Toothed gears that drive the conveyor drum are about $4000 \mathrm{~h}$, while, for example, toothed gears that drive a caterpillar transport mechanism are less than $1000 \mathrm{~h}$. Corrective measures can be achieved by applying higher quality oils in gearboxes that work for more than $6000 \mathrm{~h}$.

Corrective measures can also be taken in the application of frequency-controlled motors on all gearboxes. With motors like this, shocks at startup would be avoided, as the electric motor would gradually increase the torque. Also, mandatory use of sensors, for both temperature and vibrations, would automatically shut down gearboxes that have malfunctioned.

Part of the improvement can be achieved by eliminating the human factor in the form of unprofessional maintenance of both the lubrication system and the entire gearbox.

Other factors that cause gearbox elements to fail are related to the element materials themselves. Corrective measures can be achieved by applying a material with a more durable dynamic strength, or, for example, by applying a material with increased wear resistance of the gear contact surfaces, in order to reduce material fatigue failure.

Second, heat processing can be crucial. It is known that the service life of gears is extended if the flanks and roots are tempered as a whole and if the depth of the surface-tempered layer is great, so some corrective measures can be taken in this area as well.

\section{CONCLUSION}

This paper presents an analysis of gearbox failure on Drmno open pit mine based on field analysis as well as available literature.

The current strategy used in the mining industry is not effective due to a large number of unexpected failures. The consequences of such a policy are costly, and repairs can take several days.

The results obtained from the analysis show that there were 94 failures during the whole of 2017 , of which: $(40.1 \%)$ on oil seals, $(38.8 \%)$ on bearings, $(4.2 \%)$ on bevel gears, $(1,3 \%)$ on cylindrical gears, $(1 \%)$ on worm gears, $(3.5 \%)$ on toothed inlet shafts, $(0.3 \%)$ on central toothed shafts, $(0.3 \%)$ on stepped shafts with groove, $(5.3 \%)$ on coupling rubber inserts and $(1.7 \%)$ on cover screws.

On the basis of the resulting malfunctions, a fault tree was formed which gives the possibility to determine the most serious malfunctions and the causes that lead to them.

Some improvements that do not require a lot of money but significantly improve the reliability of gearboxes can be achieved by mandatory oil filtration and finer sieves, use of fan-shaped nozzles for gear lubrication, mandatory oil change, and use of higher exploitation hour oils for gearboxes which are mostly exploited, use of electric motors with frequency regulators, in the construction of new and reconstruction of existing systems, as this allows to reduce the shock at startup, use of sensors to monitor the basic parameters, continuous education of staff and pointing out the consequences of improper handling. 


\section{REFERENCES}

[1] J.X. Li, X.X. Pang, Y.J. Li, Research of Dynamic Characteristic of Belt Conveyor, 3rd Annual International Conference on Mechanics and Mechanical Engineering, 105, 2016: 304-312. https://doi.org/10.2991/mme-16.2017.42

[2] Z. Q. Chen, C. Li, R. V. Sanchez, Gearbox Fault Identification and Classification with Convolutional Neural Networks. Shock and Vibration, 2015 (2), 2015: 1-10.

https://doi.org/10.1155/2015/390134

[3] P. Matuszewski, Condition Monitoring in BOT KWB Belchatow mine, (Ph.D. Thesis). Mining Faculty, Wrocław, 2007.

[4] N. Zuber, R. Bajrić, R. Šostakov, Gearbox faults identification using vibration signal analysis and artificial intelligence methods. Eksploatacja i Niezawodnosc - Maintenance and Reliability, 16, 2014: 61-65.

[5] R. Zimroz, R. Król, Failure analysis of belt conveyor systems. Mining Science, 128, 2009: 255-270.

[6] A. Skoć, Dynamics of bevel gears in mining machines. Wydawnictwo Politechniki Ślq̨skiej, Gliwice, 1996.

[7] W. Bartelmus, New Focus on Gearbox Condition Monitoring for Failure Prevention Technology. Key Engineering Materials, 588, 2014: 184-191.

https://doi.org/10.4028/www.scientific.net/KEM. $\underline{588.184}$

[8] B. Gerike, E. Kuzin, I. Panachev, Development of the preventive maintenance system for belt conveyors reducers, The 1st International Innovative Mining Symposium, 15, 2017: 1-6.

\section{https://doi.org/10.1051/e3sconf/20171503008}

[9] ISO 10825, Gears - Wear and damage to gear teeth - Terminology, 1995.

[10] I. Atanasovska, D. Momčilović, The effect of teeth failures on machine safety - testing and analysis. Structural integrity and life, 7 (1), 2007: 37-46.
[11] S. Tanasijević, Osnovi tribologije mašinskih elemenata. Naučna knjiga, Beograd, 1989.

[12] B. Ivković, A. Rac, Tribologija. Jugoslovensko društvo za tribologiju, Kragujevac, 1995.

[13] M. Ognjanovic, Progressive gear teeth wear and failure probability modeling. Tribology in industry, 26 (3), 2004: 44-49.

[14] R. Basan, M. Franulović, M. Lengauer, B. Križan, Rolling - sliding - contact fatigue damage of the gear tooth flanks. Engineering Review, 30 (2), 2010: 37-46.

[15] Y. Lee, J. Pan, R. Hathaway, M. Barkey: Fatigue testing and analysis - Theory and practice. Elsevier Butterwoth - Heinemann, Burlington, 2005.

[16] S. Khoshaba, V. Haralanova, Failures in gearboxes due to material problems. Materials, Methods \& Technologies, 10, 2016: 112-136.

[17] C. Moolwan, S. Neptu, Failure Analysis of a Two High Gearbox Shaft. Procedia - Social and Behavioral Sciences, 88, 2013: 154-163.

https://doi.org/10.1016/j.sbspro.2013.08.491

[18] ISO 15243 Rolling bearings - Damage and failures - Terms, characteristics and causes, 2004.

[19] G. Šiniković, Bearing damage detection in ultrasonic domain, (Ph.D. Thesis). University of Belgrade. Faculty of Mechanical Engineering, Beograd, 2012.

[20] R.K. Upadhyay, L.A. Kumaraswamidhas, S. Azam, Rolling element bearing failure analysis, Case Studies in Engineering Failure Analysis, 1 (1), 2013: 15-17.

https://doi.org/10.1016/i.csefa.2012.11.003

[21] SKF Bearing investigation, Extract from the Railway technical handbook, 1 (6), 2012: 122-135.

[22] S. Šćepović, D. Šorta, V. Šorta, Diagnostics of oil from gear-box. Tehnička dijagnostika, 8 (4), 2009: 5-10.

[23] Ć. Prolić, A. Lepušić, Effect of foaming on the antiwear properties of lubricating oils, Goriva i maziva, 51 (1), 2012: 29-46. 